\title{
El signo del anillo de sello
}

\section{Signet ring sign}

ana Cristina Manzano, MD.(1); Pablo Ramón Gil Torres, MD. (2); Milena García, MD. ${ }^{(3)}$; CARlos ANDRÉs CElis PRECIADo, MD. ${ }^{(4)}$

(1)Radióloga, IDIME. Bogotá, Colombia. ${ }^{(2)}$ Residente de Medicina Interna, Fundación Valle del Lili, Universidad ICESI. Cali, Colombia.

${ }^{(3)}$ Internista, Fellow de Neumología, Unidad de Neumología, Hospital Universitario San Ignacio. Pontificia Universidad Javeriana. Bogotá, Colombia.

${ }^{(4)}$ Internista, Neumólogo, Unidad de Neumología, Hospital Universitario San Ignacio. Pontificia Universidad Javeriana. Bogotá, Colombia.

Correspondencia: Ana Cristina Manzano, correo electrónico: crispetamanzano@ gmail.com

Recibido: 17/08/14. Aceptado: 10/09/14.
En su Glosario de Términos de Radiología Torácica, la Sociedad Fleischner lo define como una imagen en forma de anillo, conformada por el corte transversal de las paredes de un bronquio dilatado y la arteria acompañante adyacente, más pequeña (1) (figura 1).

El signo del anillo de sello es el signo tomográfico cardinal de las bronquiectasias (1). No obstante, también se ha descrito en enfermedades caracterizadas por un flujo arterial pulmonar reducido o anormal (2), en tromboembolia pulmonar crónica (3) y en hidatidosis pulmonar (4).
La interrupción proximal de la arteria pulmonar derecha es una anomalía del desarrollo poco común y se asociada con malformaciones cardiacas congénitas como defecto del septo ventricular, tetralogía de Fallot, coartación de aorta, estenosis aórtica subvalvular, transposición de grandes vasos y fístula aortopulmonar. En esta entidad la arteria se amputa de forma abrupta en el hilio y la sangre es suplida por vasos sistémicos colaterales, principalmente arterias bronquiales. Los hallazgos tomográficos se caracterizan por la ausencia completa de la porción mediastinal de la arteria pulmonar derecha y aumento de vasos colaterales.

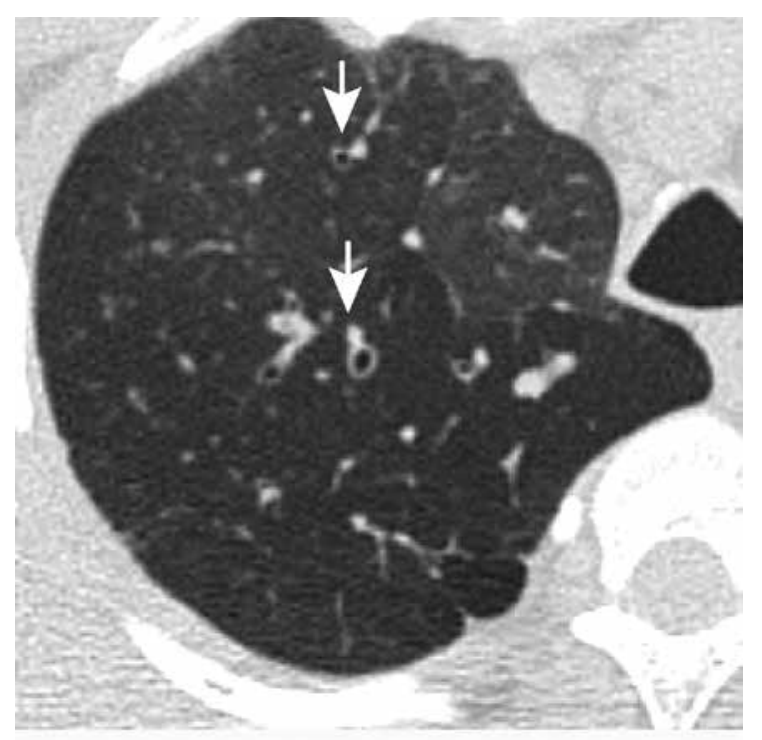

Figura 1. Signo del anillo de sello. Las flechas señalan la imagen del bronquio dilatado adyacente a su arteria de menor calibre. 
Los hallazgos en el parénquima incluyen infiltrados reticulares, engrosamiento septal, consolidación subpleural, cambios quísticos y dilatación bronquial acompañando a la pequeña arteria sistémica para constituir el signo del anillo sello. El engrosamiento bronquial y las bronquiectasias se asocian con la hipertrofia de los vasos colaterales sistémicos (2).

En tromboembolia pulmonar crónica, el mecanismo fisiopatológico descrito para la formación del signo del anillo de sello se atribuye a la disminución del tamaño de la arteria pulmonar por un efecto obstructivo crónico que causa disminución del flujo que a su vez produce una dilatación recíproca de la pared del bronquio (3).

Aunque el término "anillo de sello" ha sido ampliamente utilizado para describir este signo, en un sentido estricto, la combinación del bronquio dilatado y el vaso sanguíneo que lo acompañan simulan morfológicamente más a un anillo de perla (figura 2). Es por esto por lo que algunos autores han sugerido cambiar su nombre a signo del "anillo de perla".

\section{Bibliografía}

1. Fleishnner Society: Glossary of terms for thoracic imaging. Radiology 2008;46: 697-722.

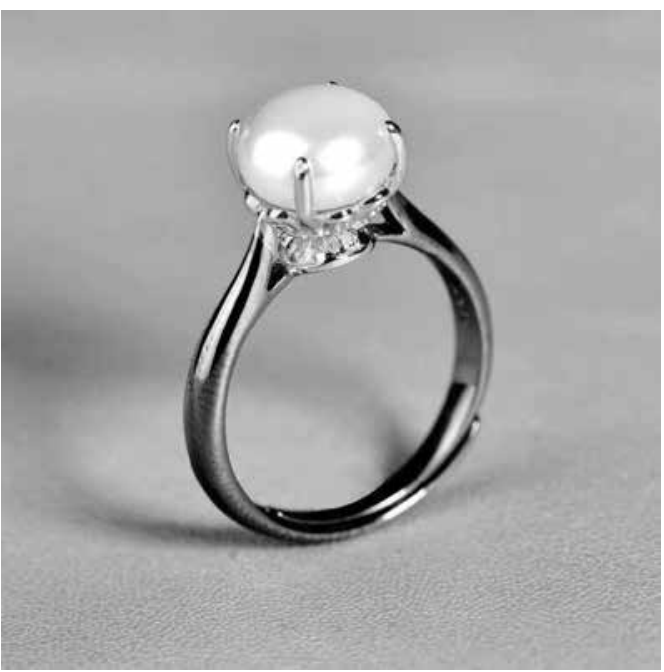

Figura 2. Anillo de perla.

2. Ryu DS, Spirn PW, Trotman-Dickenson B, Hunsaker A, Jung SM, Park MS. HRCT findings of proximal interruption of the right pulmonary artery. J Thorac Imaging. 2004;19:171-5.

3. Remy-Jardin M, Remy J, Louvegny S, Artaud D, Deschildre F, Duhamel A. Airway changes in chronic pulmonary embolism: CT findings in 33 patients. Radiology 1997;203:355-60.

4. Koul PA, Koul AN, Wahid A, Mir FA. CT in pulmonary hydatid disease: unusual appearances. Chest. 2000;118(6):1645-7.

5. Oullette, H. The signet ring sign. Radiology. 1999;212:67-8.

6. Bonavita J, Naidich DP. Imaging of bronchiectasis. Clin Chest Med. 2012;33(2):233-48 